\title{
Research and Correlation of Diagnostic Methods for Assessment of the State of Oil Filling in Cycloid Gearbox
}

\author{
Petr Baron, Marek Kočiško, Jozef Dobránsky, Martin Pollák, and Tomáš Cmorej \\ Faculty of Manufacturing Technologies, Technical University of Košice, Štúrova 31, 08001 Prešov, Slovakia \\ Correspondence should be addressed to Petr Baron; petr.baron@tuke.sk, Marek Kočiško; marek.kocisko@tuke.sk, \\ Jozef Dobránsky; jozef.dobransky@tuke.sk, Martin Pollák; martin.pollak@tuke.sk, and Tomáš Cmorej; tomas.cmorej@tuke.sk
}

Received 24 March 2015; Revised 21 September 2015; Accepted 27 September 2015

Academic Editor: Amit Bandyopadhyay

Copyright (C) 2015 Petr Baron et al. This is an open access article distributed under the Creative Commons Attribution License, which permits unrestricted use, distribution, and reproduction in any medium, provided the original work is properly cited.

The paper describes the research in the area of the application of diagnostic methods for assessment of the state of oil filling in cycloid gearbox of robotic manipulator. The experiments were realized on request of the manufacturer of the cycloid gearbox. Primarily, the two different methods were compared: an induction, magnetic method with the use of measurement system Cosmos-Steel Dust Checker and an RTG method, XRF (X-ray fluorescent method, analyses with use of X-ray radiation). These analytical methods provide the identification and quantification of emerging Fe abrasion particles occurring in the oil filling of the redactor. The results of the experiment pointed to the unsuitability of the application of the induction magnetic method for the assessment of an actual technical state of the cycloid gearbox. The reason for this lies in specific construction of the cycloid gearbox, with characteristic high operation temperatures of the oil filling, small dimensions, high transferred power, and gear ratio.

\section{Introduction}

Technical diagnostics is currently one of the most important factors of reliability and thus the operability of machinery and mechanical equipment. The key attribute of a technical system is the reliability, defined as an ability to provide desired function while preserving the operation conditions in given time. This fact increases the maintenance demands on machinery, which has to ensure the intensive use of the means of production and equipment. Methods and means of technical diagnostics are often used to achieve this objective. Technical diagnostics is now considered an academic discipline, which tracks the manifestation forms of defects, development of methods, their detection, and principles of diagnostic devices operation [1].

The area of the interest of technical diagnostics is a technical system, which is an actual or expected subject for the verification of its technical state. Technical system may be a production unit, its subgroup, machine element, a separate product, and so forth. The basic task of diagnostics is therefore to provide the diagnosis characterizing the technical condition of the system in terms of occurrence of failures.
Provided diagnosis must be usable for nursing actions optimization in order to bring the object to normal condition. The features of the diagnosed object are very important for the success of the diagnostic system. Among the most important features there is the ability to be diagnosed, which is expressed by the suitability of an object for the use of diagnostic devices. A machine is well-diagnosable when all of the diagnostic actions can be performed easily with required accuracy and possibly at little cost [2].

We verify the technical and operational state of the system, that is, all the characteristics that represent its ability to perform required functions at a given moment under defined conditions of use. For the machinery products this can be as follows $[2,3]$ :

(i) Impeccable condition, when the object satisfies all the requirements set out by production-technical documentation.

(ii) Operable condition, when the object is able to perform the defined functions and follows the values of the given parameters within the limits specified by technical documentation. 


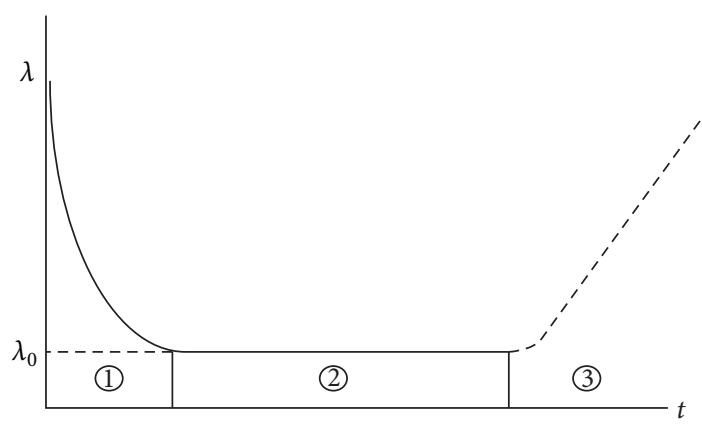

Figure 1: Bathtub curve of failure rate dependence [1]. (1) area of frequent failures, (2) area where the level of failure rate is practically constant, and (3) area where the failure rate increases due to wear of parts.

(iii) Fault condition, at which the object is unable to perform the required function within the limits specified by technical documentation.

Figure 1 depicts the relative failure of products in time. The above dependence describes the form of threat to the performance of the product function, which includes three parts:

(i) The first part is the decreasing failure rate, known as early failure.

(ii) The second part is the constant failure rate, known as random failure.

(iii) The third part is the increasing failure rate, known as wear.

Tribotechnical diagnostics is one of the methods of technical diagnostics without disassembly, which utilizes lubricants as media for obtaining information. Its task is to identify, evaluate, and report the occurrence of foreign matter in the lubricant. Appropriate interpretation of the results from the performed experiments allows not only for a timely notification on emerging failures, but also for the localization of the place of formation of mechanical error [4-6].

The decisive factor for tribotechnical diagnostics is the speed and accuracy of performed analysis. A variety of methods with different degrees of usability has been developed for the assessment. Individual types can be divided into three groups [7]:

(i) Simple tests for operational inspection of lubricants.

(ii) Standard tests for accurate determination of the lubricants' quality.

(iii) Specific methods for the overall diagnosis of lubricants and machinery equipment.

Consideration of the operational reliability of the machinery or its drive unit with use of the tribotechnical methods brings considerable economical savings in the operation. Tribotechnical elements are components of larger mechanical systems and therefore the interaction between elements of tribological system and other components is decisive for its behavior [8].
The method of detection and isolation of particles using the magnetic analyzer allows detecting the intensity of wear and clarifies the process of friction and wear. It is the diagnostic method using the particles emerging from fraction for the identification of the character of the tribological processes at friction surfaces. It allows the differentiation of the particles into size groups. The principle of the ferrography lies in the separation of the particles according to their size in strong magnetic field. It is used for the assessment of wear intensity on friction points of the aggregate. The sample of considered oil flows down the slant pad situated in magnetic field. The biggest particles are sedimented at the beginning of the transparent pad while another particles progressively according to their size and shape. The orientation on the ferrogram, the surface, and the shape of the particles are also important. Obtained ferrogram is then evaluated using the microscope. It can be evaluated in two ways, ferroscopic one (determining the morphology and the chemical constitution of the particles) and ferrodenzimetric one (evaluating the distribution of the particles in consideration of their size).

The principle of the ferrography with direct reading remains the same as in the abovementioned method, though the glass slide is replaced here with thin walled glass capillary fixed in divergent magnetic field of a special magnet. The tested oil flows through the capillary. In two places, where the large and small particles settle, there are fixed radiation sources and sensors, which sense the decrease in radiation intensity. It is directly proportional to the degree of coverage of the capillary wall with particles.

\section{Characteristics of the Realized Analyses and Description of Laboratory Results}

The objective of the realized analyses was to assess the condition of the oil filling in the cycloid gear of the manipulator (Figure 2). The condition of the solid-abrasive particles in the oil was analyzed. The objective was to identify the following relations:

(i) Run-in processes of contact surfaces, analysis of wear particles.

(ii) Methods for the quantification of total content of Fe wear particles.

(iii) Kinematic clearance (LM, lost motion), change after the run-in as a manifestation of the surface wear intensity.

(iv) Correlation, quantification of measured parameters, LM, and the Fe content of wear particles in the oil.

The tests were carried out with the focus on wear particles, which arise during the run-in or in the first hours of contact surfaces operation. At the same time, the correlation between total content of Fe particles in the oil and the increase of kinematic clearance in cycloidal gear was monitored.

Trial runs of the cycloid gearbox were in the frame of realized experiment observed from the viewpoint of the identification of abrasive particles during the first 600 hours of the operation in five tested cycloid gear pairs (oil samples A, B, 


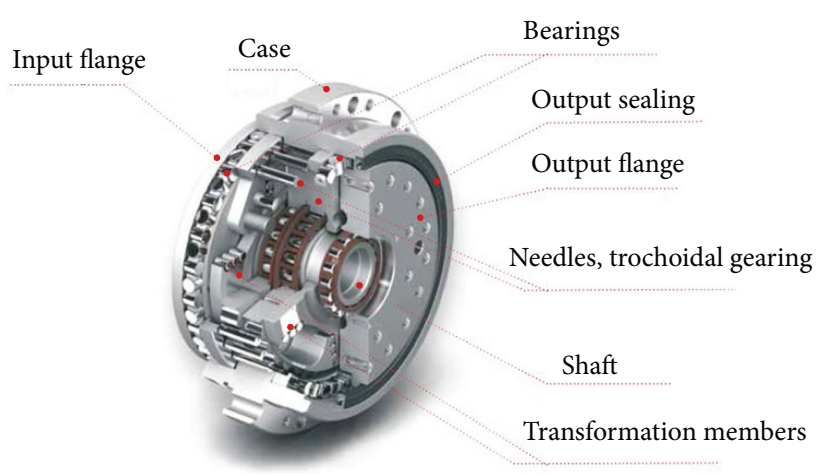

(a)

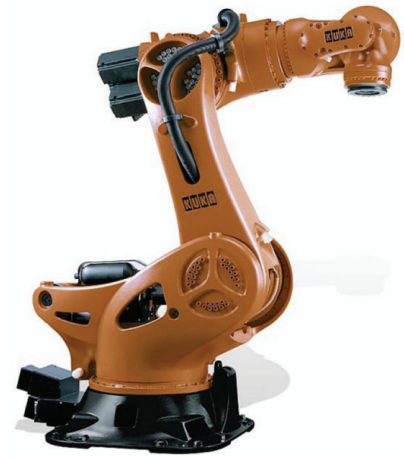

(b)

FIGURE 2: Diagnosed cycloid gearbox (a) applied in the joints of a robotic manipulator (b).

$\mathrm{C}, \mathrm{D}$, and $\mathrm{E}$ ) of the gearboxes. We compared the application possibilities for two diagnostic methods, induction method (diagnostic device Cosmos-Steel Dust Checker) and X-ray fluorescent method, for identification of the friction particles on the Fe base. Method of the ferrography analysis was used for the verification and quality description of the friction particles (their type and size).

The principle of the X-ray fluorescent spectrometry is based on the emission of secondary (or fluorescent) X-ray of the material, which was irradiated by the high-energy X-ray or gamma radiation. Analyzed atoms of the sample are driven by generated $\mathrm{X}$-rays. The electrons change their position in atomic shells and also their energetic level. These energetic differences are emitted in the form of special X-rays. Analyses of emitted energetic specter allow the accurate determination of the chemical component contained in the sample and also the assessment of its volume.

The result of the realized methods was the quantification of the total content of Fe (iron) wear particles in the assessed gear of the manipulator. At the same time, the runin processes on the contact surfaces (bearings, gears) were assessed, and they cause the following:

(i) Change in the microgeometry of surfaces, wear, and abrasive (adhesive) wear.

(ii) Contamination of the oil filling with solid particles (of abrasive nature), which cause the increase of the wear rate and accelerate the increase of teeth clearance.

By the ferrographic analysis of the lubricating oil sample (analysis of the wear particles), it is possible to identify the real operating condition of the machinery node in terms of quality of the lubrication in rolling or friction contact. In the case of repeated analysis for a certain period of operation, it is possible to determine the evolution of damage or recommend measures to improve the operation in terms of lubricationfriction mode. Ferrographic analysis (volume of $1 \mathrm{~mL}$ sample) can detect the following wear particles and solid impurities [9]:

(1) Adhesive flaky, arising in the adhesive connection of contacts. The effect of high temperature and pressure leads to the welding of the surfaces, particularly in the case of low bearing capacity or thin oil film.
(2) Abrasive spiral, formed under hard abrasion. This is often a symptom of operation in emergency mode.

(3) Fatigue, large, long-term load, formation of pitting, fatigue fracture.

(4) Laminar, flaring of the material, for example, from fatigue fracture.

(5) Spherical, typical for the wear of rolling bearing. The occurrence is caused by formation of fine cracks on the contact surfaces.

(6) Gamma-hematite, black oxidation, $\mathrm{Fe}_{3} \mathrm{O}_{4}$. The particles are a symptom of inadequate supply of lubricant to the contact (e.g., lack of lubricant, incomplete oil contact, and mechanical or thermal overload).

(7) Alpha-hematite, red oxidation $\mathrm{Fe}_{2} \mathrm{O}_{3}$. The particles indicate the presence of the water in lubricant, corrosion of friction contacts.

(8) Corrosive, occurring in the case of chemical breakdown of the lubricant.

(9) Nonferrous metallic, for example, brass, bronze, nonferrous metals.

(10) Nonferrous, for example, of fibrous or silica nature, impurities from the surroundings of the operated device.

There are several classification systems for the evaluation of the purity of lubricants. The most common is the method of determining the purity of the lubricant according to standards CSN 656206 and ISO 4406. The code of oil purity under the standard ISO 4406 consists of two numbers (e.g., 15/12). The first number is assigned by the number of identified solid particles of size greater than $5 \mu \mathrm{m}$. The second number is assigned by the number of identified solid particles of size greater than $15 \mu \mathrm{m}$. The assignment of the number of particles to the code numbers is listed in Table 1.

The following parameters were identified by the evaluation of the lubricant with respect to the content of impurities (Table 2):

(i) CN: total impurities in the lubricant according to STN 656210 . 
TABLE 1: Representation of the number of solid particles in the lubricant by code classification.

\begin{tabular}{lcc}
\hline $\begin{array}{c}\text { Number of particles in } 1 \mathrm{~mL} \text { sample } \\
\text { More than }\end{array}$ & Code number \\
\hline 80,000 & 160,000 & 24 \\
40,000 & 80,000 & 23 \\
20,000 & 40,000 & 22 \\
10,000 & 20,000 & 21 \\
5,000 & 10,000 & 20 \\
2,500 & 5,000 & 19 \\
1,300 & 2,500 & 18 \\
640 & 1,300 & 17 \\
320 & 640 & 16 \\
160 & 320 & 15 \\
80 & 160 & 14 \\
40 & 80 & 13 \\
20 & 40 & 12 \\
10 & 20 & 11 \\
5 & 10 & 10 \\
\hline
\end{tabular}

(ii) The amount of carbon in the lubricant (carbonization residue) indicated in the catalogue of lubricants as CCT number. It determines the degree of thermal oxidation for gear, hydraulic, compressor, turbine oils, and gasoline and diesel engines. The limit value ranges from $2.0 \%$ to max. $2.5 \%$.

(iii) DL: the number of large wear particles (over $15 \mu \mathrm{m}$ ), determined using direct reading magnetic analyzer.

(iv) DS: the number of small and medium wear particles (1-15 $\mu \mathrm{m})$, determined using direct reading magnetic analyzer.

(v) WPC: the amount of wear particles, indicating the level of the system wear.

(vi) PLP: the proportion of macroparticles on WPC, indicating the intensity of the lubrication wear.

(vii) Inspection of appearance and colour, according to STN 656076 and ISO 2049.

(viii) Flash point in a closed crucible, according to STN 656064 and ISO 2719.

(ix) Water content, according to STN 656062 and DIN 51777.

The results of the analyses of the condition of the monitored lubricant within the realized experiment were verified by two methods (Table 3, Figure 3):

(1) Induction, magnetic method using the measuring system Cosmos-Steel Dust Checker.

(2) X-ray, XRF (X-ray fluorescence method, analysis by $\mathrm{X}$-ray).

The objects of the performed analysis were selected industrial gear oils based on PAO and PG, high performance synthetic

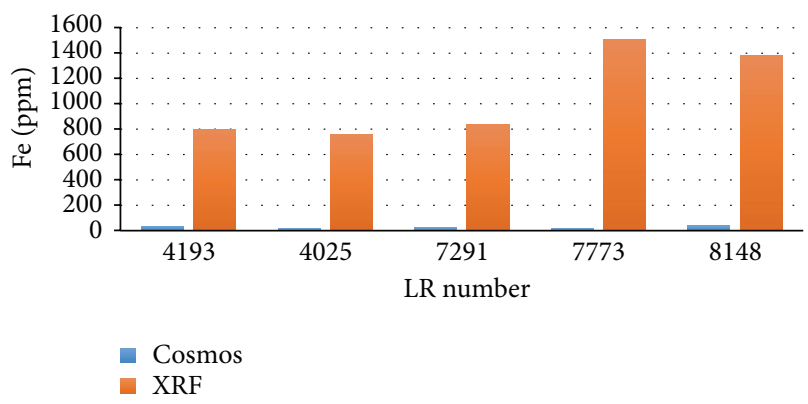

Figure 3: Content of Fe in the gear oil for samples A-E.

oils (HPL class). The analysis of the Fe content (ppm) was performed in gear oil, Optigear RO-220 (samples A-E).

The results of the analysis are summarized in Table 3.

The measured values (total content of contaminants, water, small and large particles, and $\mathrm{Fe}$ ) for sample A are listed in Table 4; photos of ferrographics record for objective sample are in Figure 4.

The photos (Figures 4-8) show examples of ferrograms, ferrographic traces, obtained for different oil samples, with different content of Fe wear particles.

The measured values (total content of contaminants, water, small and large particles, and $\mathrm{Fe}$ ) for sample B are listed in Table 5; photos of ferrographics record for objective sample are in Figure 5.

The measured values (total content of contaminants, water, small and large particles, and $\mathrm{Fe}$ ) for sample $\mathrm{C}$ are listed in Table 6; photos of ferrographics record for objective sample are in Figure 6.

The measured values (total content of contaminants, water, small and large particles, and $\mathrm{Fe}$ ) for sample $\mathrm{D}$ are listed in Table 7; photos of ferrographics record for objective sample are in Figure 7.

The measured values (total content of contaminants, water, small and large particles, and $\mathrm{Fe}$ ) for sample $\mathrm{E}$ are listed in Table 8; photos of ferrographics record for objective sample are in Figure 8.

\section{Correlation, Quantification of Measured Parameters, and Recommended Limits}

The realized measurements and the assessment of interrelations show correlation between

(i) individual oil samples, showing the presence and intensity of run-in processes,

(ii) microdgeometrical quality of contact surfaces and surfaces run-ins,

(iii) increase of kinematic clearance depending on the content of Fe abrasive (adhesive) particles in oil filling (Figure 9).

Completed analyses proved the existence of certain limits for the assessment of the content of Fe particles in gear oils using a simpler method, induction, magnetic method using the measurement system Cosmos-Steel Dust Checker before 
TABLE 2: Evaluation of the lubricant condition.

\begin{tabular}{lcccc}
\hline \multirow{2}{*}{ Parameter } & Good & Satisfactory & Condition evaluation & Unsatisfactory \\
& - & $1.7-2.0 \%$ & $2.0-2.5 \%$ & Emergency \\
\hline CN-total impurities (CCT IR) & - & To $50 \%$ & $50-70 \%$ & Over 70\% \\
WPC-amount of wear particles & - & To $15 \%$ & $15-35 \%$ & Over $35 \%$ \\
PLP-proportion of macroparticles on WPC & - & To 2\% of the volume & Over 2\% of the volume & - \\
$\mathrm{H}_{2} \mathrm{O}-$-water content in oil & &
\end{tabular}

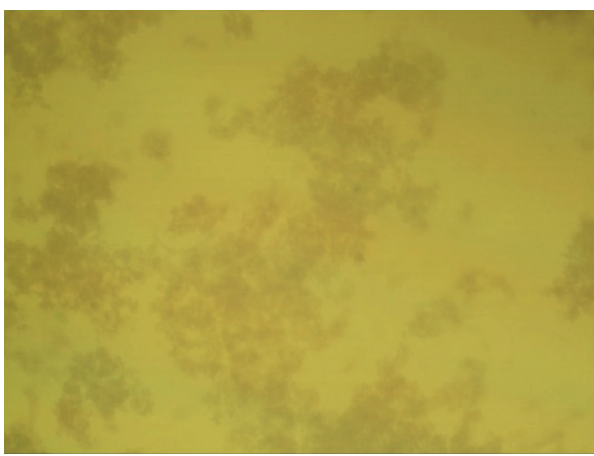

(a)

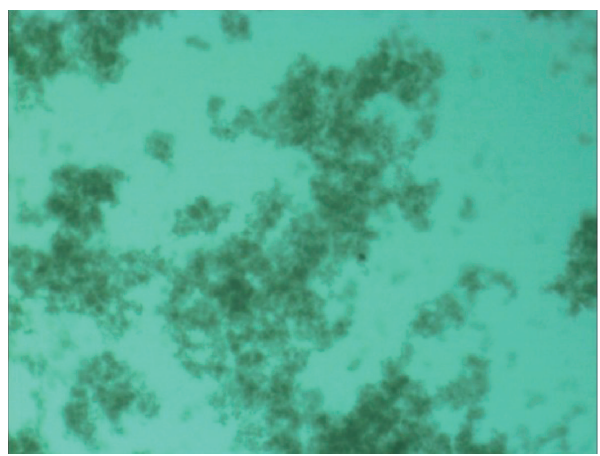

(b)

Figure 4: Photos of ferrographic record for sample A: (a) bottom light, (b) upper light.

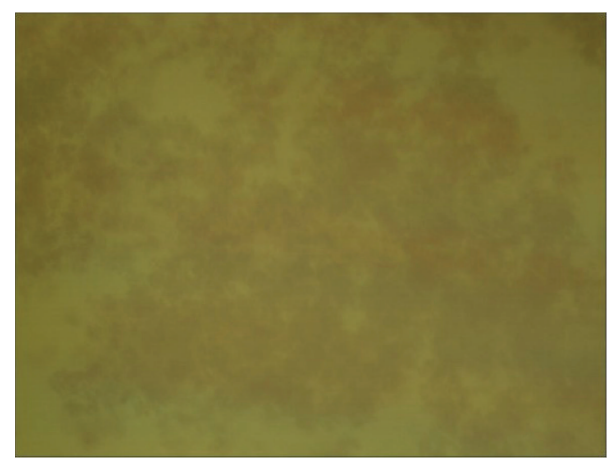

(a)

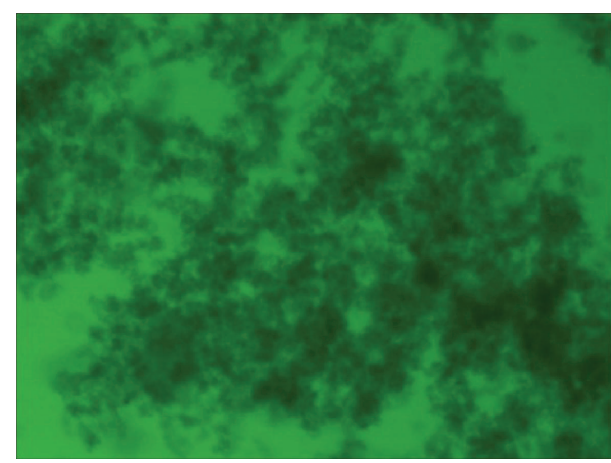

(b)

Figure 5: Photos of ferrographic record for sample B: (a) bottom light, (b) upper light.

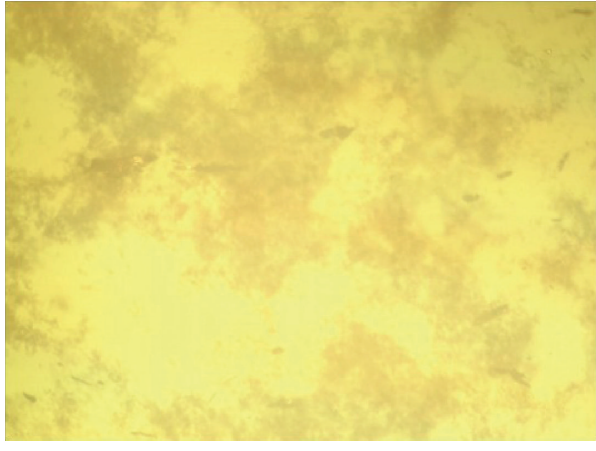

(a)

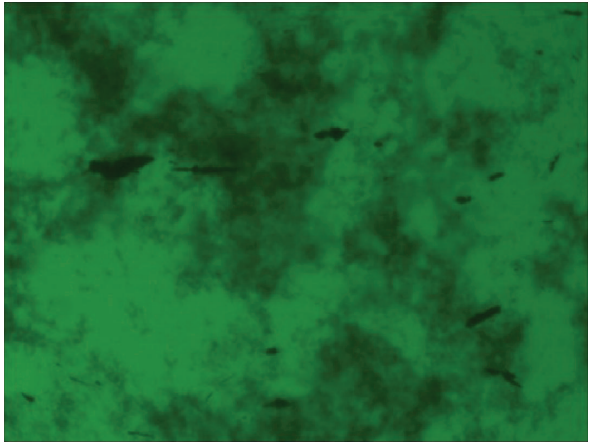

(b)

FIGURE 6: Photos of ferrographic record for sample C: (a) bottom light, (b) upper light. 


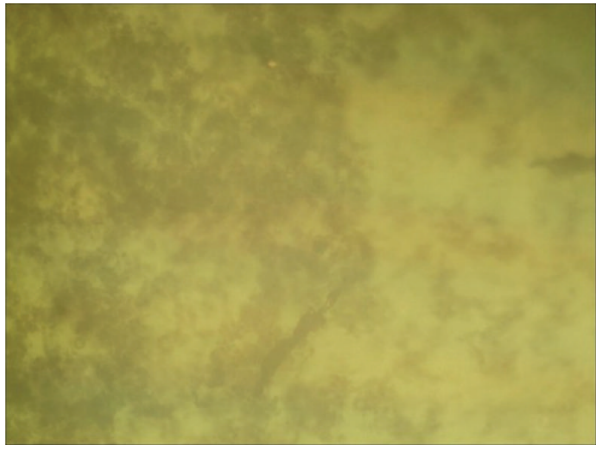

(a)

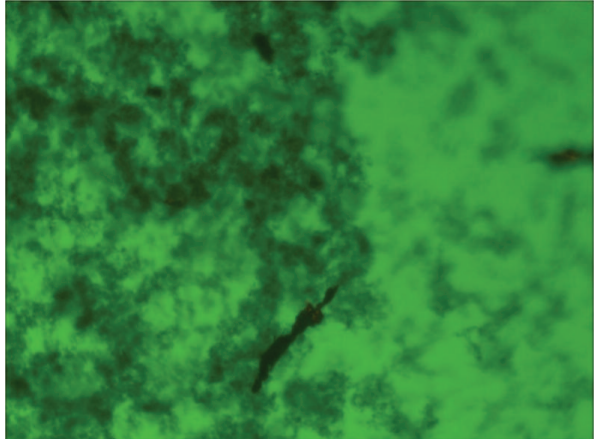

(b)

Figure 7: Photos of ferrographic record for sample D: (a) bottom light, (b) upper light.

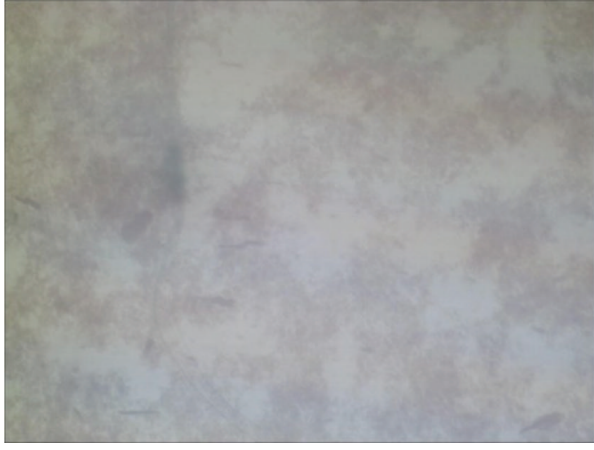

(a)

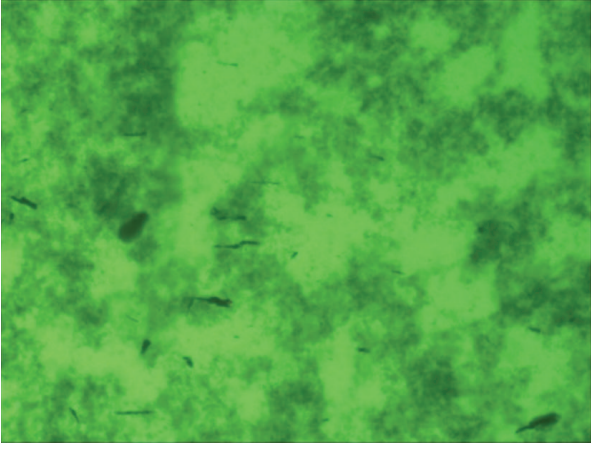

(b)

FIGURE 8: Photos of ferrographic record for sample E: (a) bottom light, (b) upper light.

TABLE 3: Results of the realized experiments.

\begin{tabular}{lcccc}
\hline \multirow{2}{*}{ Serial number } & \multirow{2}{*}{ Sample } & LR number & \multicolumn{2}{c}{ Fe content (ppm) } \\
& & & Cosmos & XRF \\
\hline 1 & A & 4,193 & 36 & 800 \\
2 & B & 4,025 & 18 & 760 \\
3 & C & 7,291 & 24 & 840 \\
4 & D & 7,773 & 19 & 1,510 \\
5 & E & 8,148 & 38 & 1,380 \\
\hline
\end{tabular}

more sophisticated X-ray fluorescence method, analysis by Xray (Figure 10).

\section{Discussion of Realized Experiments}

Cycloid gearboxes used in manipulators and robotic applications are characterized by the following operational conditions:

(i) Low weight and small dimensions.

(ii) High transmitted power (input operating speed and torque).

(iii) High gear ratio (50 to 130).

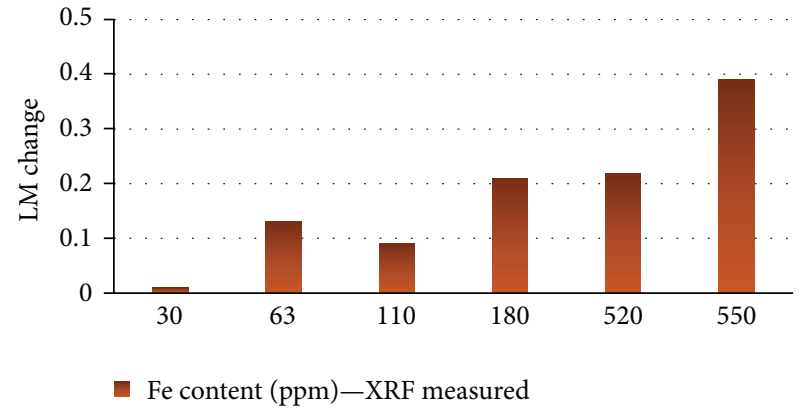

FIgURE 9: Correlations between LM and Fe content (ppm).

(iv) High operational temperature of the oil (above $90^{\circ} \mathrm{C}$ ) and at the same time small volume of oil filling ( 0.3 to $1.0 \mathrm{~kg})$,

(v) Operational cycle with variable speeds, high angle acceleration, and often change of running direction.

As a standard for this type of reductors, it is usually required that it will not come to the change of torsional stiffness and formation of mechanic clearance (so called lost motion) during the entire life cycle (normally 16.000 hours of permanent operation in working cycle). That would mean 
TABLE 4: The measurement results for sample A.

\begin{tabular}{|c|c|c|c|c|c|c|c|}
\hline & $\begin{array}{c}\text { Total impurities } \\
\text { CCT IR } \\
{[\%]}\end{array}$ & $\begin{array}{c}\text { Water } \\
\mathrm{H}_{2} \mathrm{O} \\
{[\%]}\end{array}$ & $\begin{array}{c}\text { Large particles } \\
\text { DL } \\
\text { Number }\end{array}$ & $\begin{array}{c}\text { Small particles } \\
\text { DS } \\
\text { Number }\end{array}$ & $\begin{array}{c}\text { WPC } \\
{[\%]}\end{array}$ & $\begin{array}{l}\text { PLP } \\
{[\%]}\end{array}$ & $\begin{array}{c}\text { Fe content } \\
\text { (Cosmos) } \\
{[\mathrm{ppm}]}\end{array}$ \\
\hline Range & $0-2$ & $0-2$ & $0-900$ & $0-900$ & $0-100$ & $0-50$ & $0-1,500$ \\
\hline Reality & 1.9 & & 40 & 10 & 3 & 1 & 36 \\
\hline
\end{tabular}

TABLE 5: The measurement results for sample B.

\begin{tabular}{|c|c|c|c|c|c|c|c|}
\hline & $\begin{array}{c}\text { Total impurities } \\
\text { CCT IR } \\
{[\%]}\end{array}$ & $\begin{array}{c}\text { Water } \\
\mathrm{H}_{2} \mathrm{O} \\
{[\%]}\end{array}$ & $\begin{array}{c}\text { Large particles } \\
\text { DL } \\
\text { Number }\end{array}$ & $\begin{array}{c}\text { Small particles } \\
\text { DS } \\
\text { Number }\end{array}$ & $\begin{array}{c}\text { WPC } \\
{[\%]}\end{array}$ & $\begin{array}{l}\text { PLP } \\
{[\%]}\end{array}$ & $\begin{array}{c}\text { Fe content } \\
\text { (Cosmos) } \\
{[\mathrm{ppm}]}\end{array}$ \\
\hline Range & $0-2$ & $0-2$ & $0-900$ & $0-900$ & $0-100$ & $0-50$ & $0-1,500$ \\
\hline Reality & 1.9 & & 25 & 10 & 2 & 1 & 18 \\
\hline
\end{tabular}

TABLE 6: The measurement results for sample C.

\begin{tabular}{|c|c|c|c|c|c|c|c|}
\hline & $\begin{array}{c}\text { Total impurities } \\
\text { CCT IR } \\
{[\%]} \\
\end{array}$ & $\begin{array}{l}\text { Water } \\
\mathrm{H}_{2} \mathrm{O} \\
{[\%]}\end{array}$ & $\begin{array}{c}\text { Large particles } \\
\text { DL } \\
\text { Number }\end{array}$ & $\begin{array}{c}\text { Small particles } \\
\text { DS } \\
\text { Number }\end{array}$ & $\begin{array}{c}\text { WPC } \\
{[\%]}\end{array}$ & $\begin{array}{l}\text { PLP } \\
{[\%]}\end{array}$ & $\begin{array}{c}\text { Fe content } \\
(\text { Cosmos }) \\
{[\mathrm{ppm}]} \\
\end{array}$ \\
\hline Range & $0-2$ & $0-2$ & $0-900$ & $0-900$ & $0-100$ & $0-50$ & $0-1,500$ \\
\hline Reality & 2.0 & & 30 & 15 & 3 & 1 & 24 \\
\hline
\end{tabular}

TABLE 7: The measurement results for sample D.

\begin{tabular}{|c|c|c|c|c|c|c|c|}
\hline & $\begin{array}{c}\text { Total impurities } \\
\text { CCT IR } \\
{[\%]}\end{array}$ & $\begin{array}{c}\text { Water } \\
\mathrm{H}_{2} \mathrm{O} \\
{[\%]}\end{array}$ & $\begin{array}{c}\text { Large particles } \\
\text { DL } \\
\text { Number }\end{array}$ & $\begin{array}{c}\text { Small particles } \\
\text { DS } \\
\text { Number }\end{array}$ & $\begin{array}{c}\text { WPC } \\
{[\%]}\end{array}$ & $\begin{array}{l}\text { PLP } \\
{[\%]}\end{array}$ & $\begin{array}{c}\text { Fe content } \\
\text { (Cosmos) } \\
{[\mathrm{ppm}]}\end{array}$ \\
\hline Range & $0-2$ & $0-2$ & 0-900 & $0-900$ & $0-100$ & $0-50$ & $0-1,500$ \\
\hline Reality & 2.0 & & 40 & 15 & 3 & 1 & 19 \\
\hline
\end{tabular}

TABLE 8: The measurement results for sample E.

\begin{tabular}{|c|c|c|c|c|c|c|c|}
\hline & $\begin{array}{c}\text { Total impurities } \\
\text { CCT IR } \\
{[\%]}\end{array}$ & $\begin{array}{c}\text { Water } \\
\mathrm{H}_{2} \mathrm{O} \\
{[\%]}\end{array}$ & $\begin{array}{c}\text { Large particles } \\
\text { DL } \\
\text { Number }\end{array}$ & $\begin{array}{c}\text { Small particles } \\
\text { DS } \\
\text { Number }\end{array}$ & $\begin{array}{c}\text { WPC } \\
{[\%]}\end{array}$ & $\begin{array}{l}\text { PLP } \\
{[\%]}\end{array}$ & $\begin{array}{c}\text { Fe content } \\
(\text { Cosmos }) \\
{[\mathrm{ppm}]}\end{array}$ \\
\hline Range & $0-2$ & $0-2$ & $0-900$ & $0-900$ & $0-100$ & $0-50$ & $0-1,500$ \\
\hline Reality & 2.0 & & 18 & 10 & 2 & 1 & 38 \\
\hline
\end{tabular}

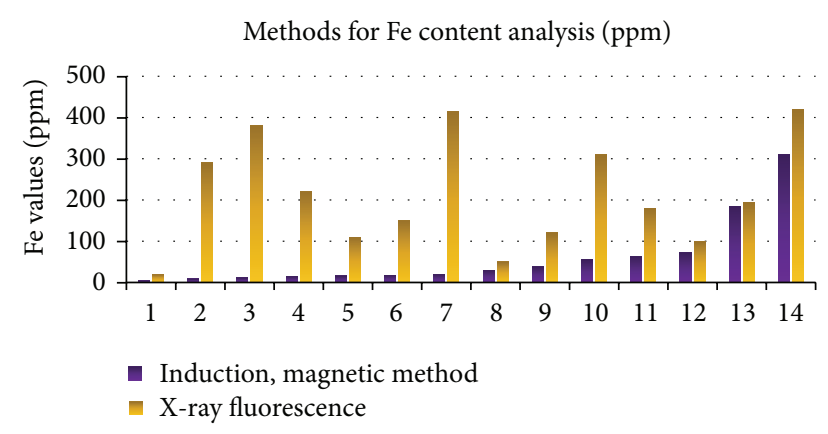

FIGURE 10: Comparison of the results of analyses by Cosmos and XRF methods. the increase of torsional vibrations on the gearbox output and difficulties in control and regulation of the actuator.

Cycloid gearbox transmits a mechanical output from the actuator to the output arm through individual components, contact surfaces (bearings, gearing, and the like). For reliable operation it is very important for entire life cycle of the gearbox (manipulator/robot) to avoid excessive wear at the contact surfaces (adhesive/abrasive friction particles of $\mathrm{Fe}$ type).

In consideration of the quality/quantity of emerging $\mathrm{Fe}$ friction particles there is a series of analytical methods for the analyses of oil sample. With use of such methods we judge the changes of chemical and physical attributes of utilized 
gear oils. With use of trend analyses of selected parameters of manipulator or robot

(i) we can determine operational state of gear lubricating oil and the state of contact surface of individual components for transmission of mechanical power,

(ii) in case of increased volume of Fe friction parts we can understand the tribotechnical mechanism, in which the particles are generated.

Analyses and the knowledge obtained from the test serve as the base for evaluation of the durability of the cycloid gearbox and also as a uncommonly valid information for research and optimization of the inner construction of the components for the transmission of the mechanical power of contact surfaces $[10,11]$.

In the frame scope of realized experiments, we evaluated the state of oil fillings for 5 identical gearboxes (samples labeled as A, B, C, D, and E). We monitored processes of trial runs of cycloid gearbox from the viewpoint of identification of abrasive particles in first 600 hours of operation for individual gearboxes. On the base of the requirement of robotic manipulator producer, primarily two different diagnostic methods were tested, induction method (diagnostic device Cosmos-Steel Dust Checker) and X-ray fluorescent method, for identification of abrasive friction particles on Fe base. Method of ferrography was used for the verification and qualitative description of the friction particles (their type and size).

Experiment pointed out the fact that trial run for observed type of gearing includes the generation of friction particles from contact surfaces of gearing and bearings, which often have the form of magnetic compounds on the $\mathrm{Fe}$ base (i.e., oxides such as $\mathrm{FeO}, \mathrm{Fe}_{2} \mathrm{O}_{3}, \mathrm{Fe}_{3} \mathrm{O}_{4}$, and complex compounds, i.e., with additives such as Mo, S, $\mathrm{Fe}$, and $\mathrm{Ca})$. The reason for generation of these compounds lies in constructional solution of the cycloid gearbox, which is characterized by small dimensions, which leads to the higher operation temperatures of the oil filling together with increase of the pressure inside the reductor. There were also particles with dimensions less than $5 \mu \mathrm{m}$ generated.

Listed circumstances result in notable differences in measured values of Fe volume ( $\mathrm{ppm}$ ) obtained by Cosmos and XRF methods (Table 3). While after using of induction method the values are below the level of acceptable limits (100 Fe ppm), XRF method locates the samples into the area far beyond the recommended limit.

Induction method represents a cheap and quick method for operative, trendy measurement and analyses of the oil sample. Yet after identification of its restrictions, it finds its application with other types of mechanisms, which are not under specific constructional and operational conditions characteristic for cycloid gearboxes (Figure 10).

XRF, RTG ray fluorescent, method is more demanding in time and costs, but its application is inevitable in cases, where the sample includes high level of Fe friction particles of small size which are chemically bound in magnetic form.

\section{Conclusion}

The following findings can be concluded on the basis of realized experiments:

(1) Induction and magnetic methods for the detection of the content of Fe particles are not sufficiently sensitive to

(i) small particles of size under $5 \mu \mathrm{m}$,

(ii) nonmagnetic particles (e.g., some Fe oxides or complex Fe and additive compounds from gear oil, wear particles from contact surfaces).

(2) Because of the rapid increase of LM, which is undesirable in this type of driving gear, it is important to monitor the total content of Fe particles, including the small and nonmagnetic Fe wear particles.

The content of Fe particles in oil or lubricant was analyzed by Cosmos and XRF methods. The experiment confirmed these arguments:

(i) There is a fundamental difference in the measured values of Fe content according to the method used.

(ii) Induction method in this case does not guarantee the correct quantification of measured Fe particles concentrations (wear particles from contact surfaces).

The results of analyses of individual samples using the XRF method confirmed the following:

(1) All examined samples contain a large number of ferrous wear particles.

(2) Examined samples simultaneously show a high thermal and oxidative degradation of contact surfaces, and the Fe particles are in the form of oxides and complex compounds (Mo, P, S, and Ca additives)

The above findings lead to a clear recommendation of the X-ray and XRF methods (X-ray fluorescence methods, analysis by $\mathrm{X}$-ray) for the verification of condition of oils and lubricants for similar types of technical systems and devices.

\section{Conflict of Interests}

The authors declare that there is no conflict of interests regarding the publication of this paper.

\section{Acknowledgment}

Ministry of Education, Science, Research and Sport of SR supported this work, Contract VEGA No. 1/0032/12 and ITMS Project 26220220125.

\section{References}

[1] I. Janouek, J. Kozák, O. Taraba et al., Technical Diagnostics, SNTL, Praha, Czech Republic, 1988.

[2] J. Balog, A. Chovanec, and M. Kianicová, Technical Diagnostics, TnUAD, Trenčín, Slovakia, 2003. 
[3] J. Sekereš and J. Turis, "Tribology as a part of machine nodes design," Scientific Studies, Technical University in Zvolen, Zvolen, Slovakia, 2009.

[4] I. A. Ushakov, V. V. Bolotin, G. N. Cherkesov et al., Handbook of Reliability Engineering, John Wiley \& Sons, New York, NY, USA, 1994.

[5] J. Dobránsky, H. Al Hakim, and P. Čačko, “Tribotechnical diagnostics as an integral part of vehicles service," Technical Weekly, vol. 57, no. 24, p. 27, 2009.

[6] J. Dobránsky and R. Krehel, "The analysis of oil quality and vibration measurement center lathe SV 18RA," Manufacturing Technology, vol. 14, pp. 33-36, 2010.

[7] J. Dobránsky and R. Krehel, "Check oil quality in machine tools using tribotechnical diagnostics," Tribotechnics, vol. 3, pp. 4647, 2009.

[8] H. Czichos, Handbook of Technical Diagnostics: Fundamentals and Application to Structures and Systems, Springer, Berlin, Germany, 2012.

[9] E. Ragan, J. Dobránsky, P. Baron, and T. Olejár, "Materials on dies for pressure die casting," Metalurgija, vol. 51, no. 1, pp. 117120, 2012.

[10] V. Simkulet, I. Vojtko, M. Kočiško, and P. Baron, "Microstructures characteristic evaluation of carbon steel C45 after new turning method by master block," World Academy of Science, Engineering and Technology, no. 78, pp. 664-666, 2013.

[11] J. Novák-Marcincin, P. Szentivanyi, M. Janák, and J. Barna, "Diagnostic of manufacturing devices operational states by smart-phones application with use of augmented reality methods," Applied Mechanics and Materials: Operation and Diagnostics of Machines and Production Systems Operational States 2, vol. 616, pp. 3-10, 2014. 

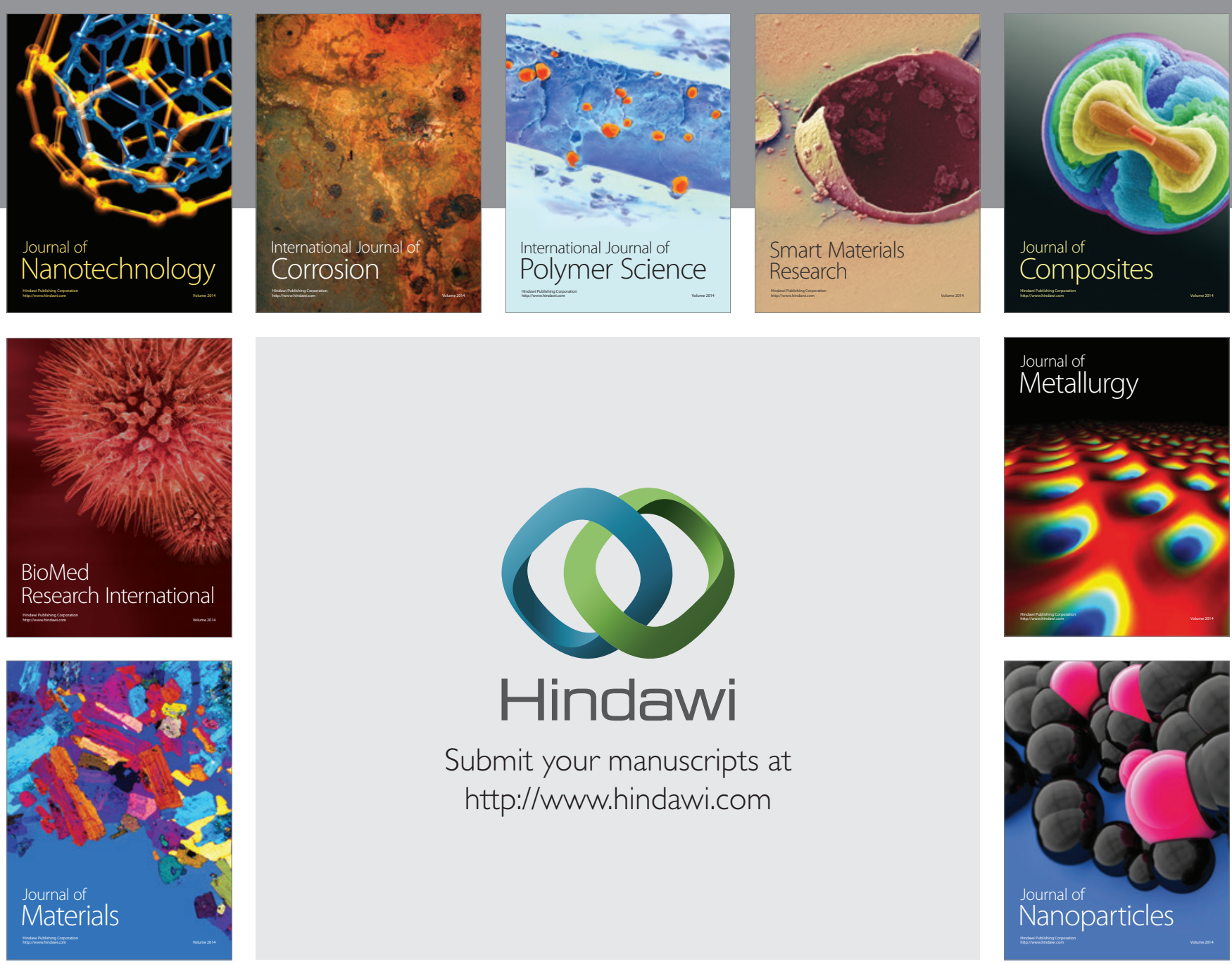

Submit your manuscripts at http://www.hindawi.com
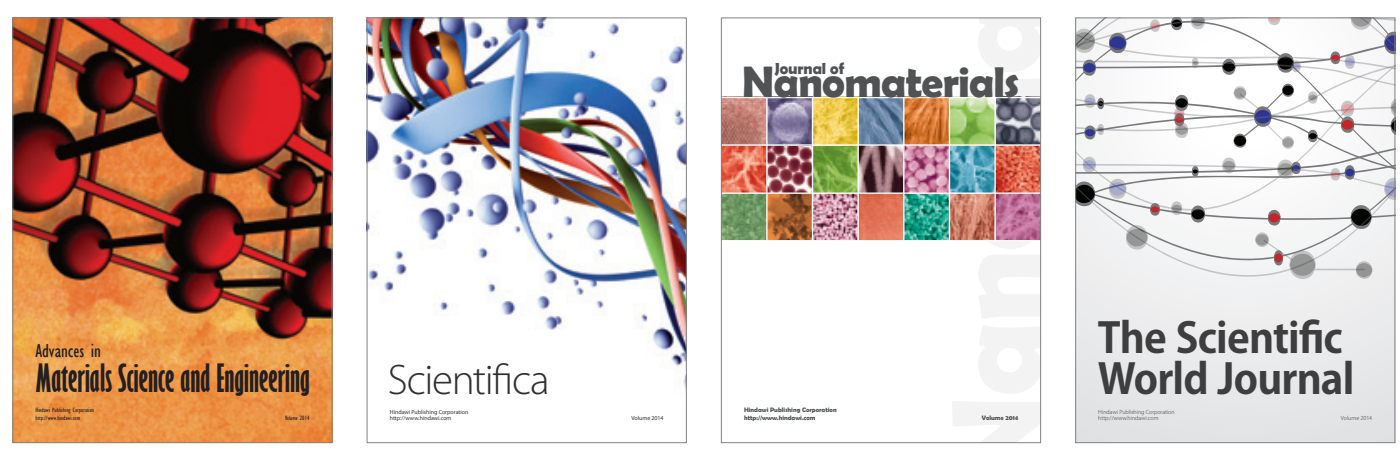

\section{The Scientific World Journal}
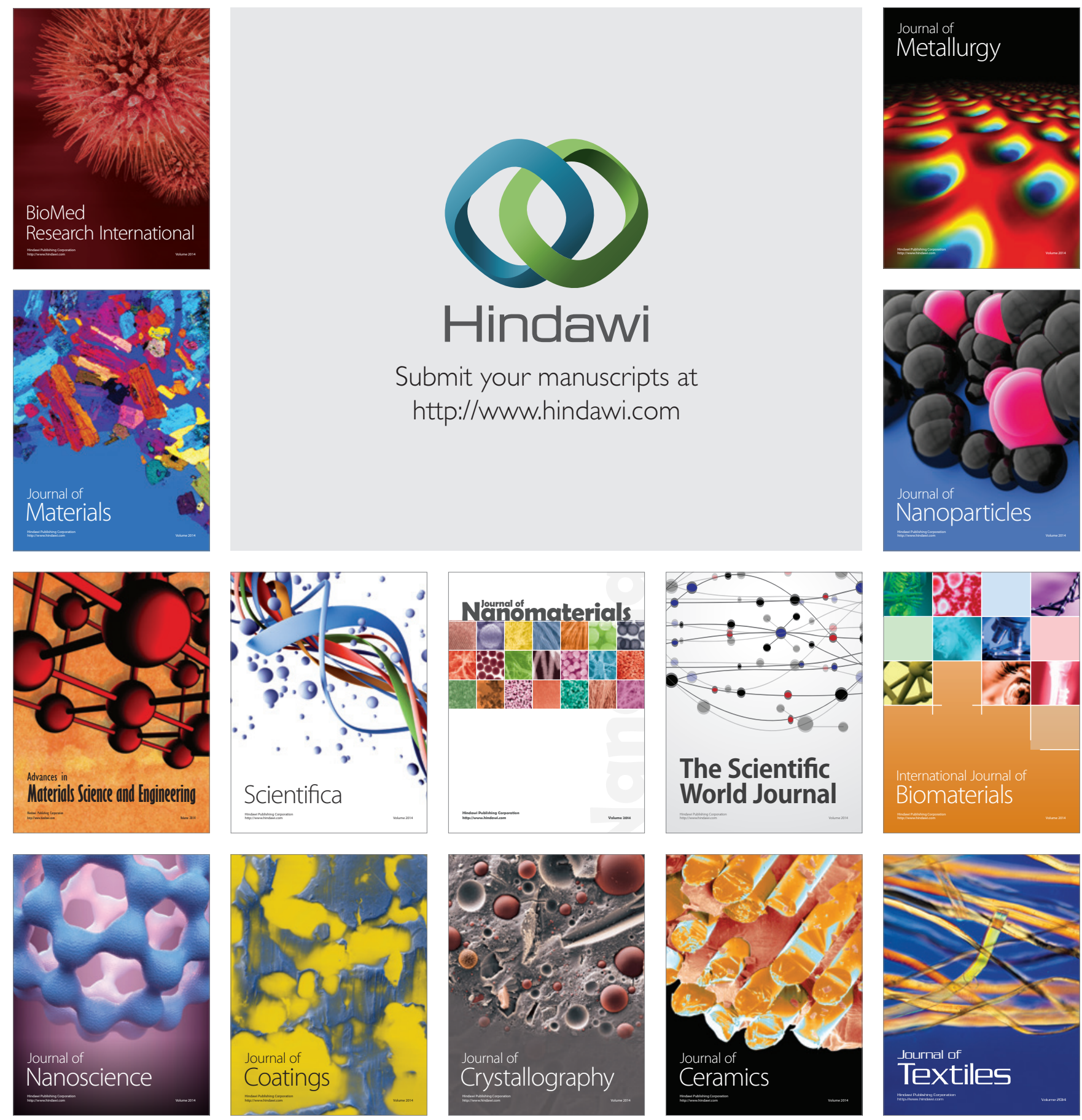